\title{
Perspectives on Global Water SeCURity
}

\author{
R. D. Harmel, I. Chaubey, S. Ale, A. P. Nejadhashemi, S. Irmak, K. C. DeJonge, \\ S. R. Evett, E. M. Barnes, M. Catley-Carlson, S. Hunt, I. Mani
}

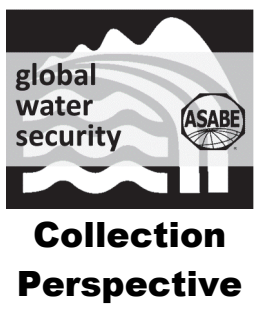

HighLIGHTS

- ASABE and ISAE convened the Global Water Security Conference for Agriculture and Natural Resources in Hyderabad, India, in 2018.

- Recommendations represent collective contribution of attendees and presenters in seven key priorities.

- Continuation of a narrow focus on technical aspects will likely prevent the success of technical solutions.

- Scientists and engineers should work together across all disciplines and boundaries to ensure global water security.

Keywords. Climate change, Crop water productivity, Food security, Irrigation efficiency, Natural resource policy, Wastewater reuse, Water resource infrastructure, Water scarcity.

A chieving global water security is a life-saving mission to address one of the most alarming problems of the 21 st century according to Ms. Katherine B. Hadda (U.S. Consul General, India). With these words, Ms. Hadda kicked off the Global Water Security Conference for Agriculture and Natural Resources in Hyderabad, Telangana, India, in October 2018. Ms. Hadda emphasized that global food security and global security itself are inexorably linked to global water security.

\footnotetext{
(c) (1) $\ominus$ The authors have paid for open access for this article. This work is licensed under a Creative Commons Attribution-NonCommercial-NoDerivatives 4.0 International License https://creative commons.org/licenses/by-nc-nd/4.0/

Submitted for review in May 2019 as manuscript number NRES 13524; approved for publication as a Perspective and as part of the Global Water Security Collection by the Natural Resources \& Environmental Systems Community of ASABE in September 2019.

Mention of company or trade names is for description only and does not imply endorsement by the USDA. The USDA is an equal opportunity provider and employer.

The authors are R. Daren Harmel, Director, USDA-ARS Center for Agricultural Resources Research, Fort Collins, Colorado; Indrajeet Chaubey, Dean, College of Agriculture, Health, and Natural Resources, University of Connecticut, Storrs, Connecticut; Srinivasulu Ale, Associate Professor, Texas A\&M AgriLife Research, Vernon, Texas; A. Pouyan Nejadhashemi, University Foundation Professor, College of Engineering, Michigan State University, East Lansing, Michigan; Suat Irmak, Distinguished Professor, Department of Biological Systems Engineering, University of Nebraska, Lincoln, Nebraska; Kendall C. DeJonge, Research Agricultural Engineer, USDA-ARS Center for Agricultural Resources Research, Fort Collins, Colorado; Steven R. Evett, Research Soil Scientist, USDA-ARS Conservation and Production Research Laboratory, Bushland, Texas; Edward M. Barnes, Senior Director of Agricultural and Environmental Research, Cotton Incorporated, Cary, North Carolina; Margaret Catley-Carlson, Vice-Chair, Board of Directors, Canadian Water Network, Vancouver, British Columbia, Canada; Sherry Hunt, Supervisory Civil Engineer, USDA-ARS Hydraulic Engineering Research Unit, Stillwater, Oklahoma; Indra Mani, Principal Scientist and Head of Agricultural Engineering Division, Indian Agricultural Research Institute, Indian Council of Agricultural Research, New Delhi, India. Corresponding author: R. Daren Harmel, 2150 Centre Ave., Fort Collins, CO 80526; phone: 970-492-7771; e-mail: daren.harmel@usda.gov.
}

Then in a plenary keynote address, Dr. Sonny Ramaswamy (former Director, USDA National Institute of Food and Agriculture, currently Northwest Commission on Colleges and Universities) described what he considers a "perfect storm" threatening the world and highlighting the need for global water security. In his address, Dr. Ramaswamy described the key causes for this perfect storm, highlighting rapid growth in human population, the increasing middle class and its changing dietary demands for more meat and produce, climate change, trade globalization (and the concurrent movement of pests, diseases, and invasive species), difficulty in communicating scientific findings (and public mistrust in science), and the substantial costs in time, effort, and money to ensure sustainability.

These powerful words from the opening day of the Global Water Security Conference convened by the American Society of Agricultural and Biological Engineers (ASABE) and the Indian Society of Agricultural Engineers (ISAE) highlight the gravity of the water scarcity challenge around the world. The Global Water Security Conference was the second ASABE Global Initiative Conference resulting from ASABE's 2012 Global Vision that "ASABE will be among the global leaders that provide engineering and technological solutions toward creating a sustainable world with abundant food, water, and energy, and a healthy environment." Three themes (food security, water security, and energy security) were explored in the "Global Partnerships for Global Solutions: An Agricultural and Biological Engineering Global Initiative" report (ASABE, 2015). The ASABE Global Initiative specifically called for improvement in water availability, conservation, and efficient use and provision of clean water for multiple uses (e.g., human consumption, agriculture, recreation, ecosystem services, biodiversity).

The first Global Initiative Conference, Engineering and Technology Innovation for Global Food Security, was convened October 24-27, 2016, in Stellenbosch, South Africa. That conference brought together international academic, 
government, and industry experts from six continents to meet with local stakeholders and address the challenges of producing and providing safe and healthy food in a sustainable manner for the growing population.

Although changing climate was not listed as a theme of the ASABE Global Initiative, it was certainly considered a fundamental component in achieving global food, water, and energy security. Recognizing its critical role, ASABE convened the 1st Climate Change Symposium: Adaptation and Mitigation in May 2015 in Chicago, Illinois. The conference and an associated ASABE Special Collection (Chaubey et al., 2016) addressed complex questions related to how agriculture and watershed management can mitigate and adapt to climate change impacts and covered topics such as adaptation and mitigation strategies, ecosystem health and services, agroecosystem sustainability, climate change modeling and interfacing climate models with the agroecosystem models, uncertainty and complexity, and water resources policy.

Effective and efficient water resource management at various spatial scales remains vital to enhance and sustain agricultural productivity to meet the food, fiber, feed, and fuel demands of a rapidly growing global population (Irmak, 2015). Water is not only essential for all life, it is also a necessary input for agricultural production. About 3,000 L of water are required to produce the daily food requirement for one person (WWAP, 2014). The water required to meet the food and fiber demands of the projected global population of 9 to 10 billion by 2050 represents a significant increase. Agriculture accounts for $70 \%$ to $75 \%$ of all water withdrawals globally and up to $95 \%$ in several developing countries, especially those in semi-arid and arid regions (Irmak, 2015). Irrigation has the potential to increase the yields of most crops by $100 \%$ to $400 \%$ compared to dryland or rainfed agriculture and contributes $40 \%$ of global food production on only $20 \%$ of cultivated land (WWAP, 2014). Water demand for agriculture is expected to increase by almost $20 \%$ by 2050 in efforts to meet increased food production demand (WWAP, 2014). In the next ten years, depletion of groundwater supplies in some agricultural areas from ineffective management will pose a risk to both national and global food markets (ICA, 2012; CAST, 2019). Adding to pressures on agricultural water use is a heightened awareness of the value of water in maintaining ecosystem services and environmental flows. According to the U.S. Intelligence Community Assessment, freshwater availability will not keep pace with increasing demand by 2040 in the absence of more effective water resource management (ICA, 2012). Problems related to limited fresh water resources (quantity and quality) will directly threaten food production, public health, biodiversity, energy generation, foreign policy, and international security.

The realities of increasingly scarce and polluted freshwater resources for agricultural use and ecosystem maintenance, as well as the added complications due to climate change, formed the backdrop of the 2018 ASABE/ISAE Global Water Security Conference. The conference included 21 invited keynote speakers from agencies such as the Indian Department of Agricultural Research and Education
(DARE) and its Indian Council of Agricultural Research (ICAR) as well as other national and international organizations including universities, the Food and Agriculture Organization (FAO), The World Bank, International Commission on Irrigation and Drainage (ICID), International Water Management Institute (IWMI), USDA, academia, and industry. The conference was attended by more than 320 participants representing 19 different countries, and presentations were made by 245 speakers. A panel session included farmers from the U.S. and India, as well as water resource experts from several countries discussing water security challenges and innovative solutions to those challenges. In addition, a number of students, including students funded by the USDA-NIFA, ISAE, and ICAR, actively participated and made presentations.

The Global Water Security Conference was designed to facilitate exchange of scientific ideas and technologies to address global water security issues in agroecosystems, explore transdisciplinary solutions to achieve water security from farm to global scales, and demonstrate successful water security innovations. The conference was organized around three themes:

- Agricultural water scarcity and security: Weathering water resource extremes.

- Irrigation and drainage, conservation, and water management for sustainable agricultural growth.

- Identifying, managing, and treating conventional and alternative agricultural water supplies.

This perspective article synthesizes recurring themes and recommendations on seven Key Priorities to guide future research, extension education and outreach, technology development and transfer, public-private partnerships, and policy formulation. These perspectives and recommendations represent the collective contribution of attendees and presenters at the Global Water Security Conference.

\section{ToWard Global Water SEcurity}

The 2015 ASABE Global Initiative publication (Matlock, 2015) highlighted an obvious but crucial reality: Water security is essential for sustaining life. It summarized well the challenge of global water security:

"In evaluating water resources, water quantity and quality are the determiners of water security. Human water use is approximately $3 \%$ of all on-land annual precipitation. However, access to water is not equally distributed, and its quality is degrading around the globe. It is estimated that 3,900 children die every day from waterborne diseases, one in six people lack access to safe drinking water, and decreasing river flows are greatly affecting ecosystems and human activities. In addition, $70 \%$ of worldwide freshwater consumption is used for agricultural purposes, with that percentage varying widely in different parts of the world."

The formal kick-off for the ASABE focus on global water security occurred with the keynote address and invited panel discussion at the 2018 Annual International Meeting in Detroit, Michigan. In the keynote address, Margaret CatleyCarlson (vice-chair of the Canadian Water Network Board and patron and past chair of the Global Water Partnership) 
outlined her perspectives on improving global water security.

Following Ms. Catley-Carlson's address, invited panelists (Dr. Sherry Hunt, moderator, USDA-ARS; Margaret Catley-Carlson; Dr. Indrajeet Chaubey, formerly Purdue University, College of Agriculture, Health and Natural Resources, University of Connecticut; Dr. Edward Barnes, Agricultural and Environmental Research, Cotton Incorporated; Dr. Steven Evett, USDA-ARS) provided their insights and expertise on the following questions: How are we equipped to handle water security challenges laid before us? Are there improved methods for harnessing excess water for reuse or aquifer recharge? Does technology, management, or policy provide the best return on investment in terms of producing more food with less water? The panelists noted important avenues for harvesting and storing excess water for use during periods of need, and they discussed several increasingly important technological advances that could benefit water security. However, the panelists also generally agreed that although improved technology and management are critical to enhancing water security, socio-economic and policy considerations often play the controlling role. They also pointed out that the technical solutions developed are unlikely to succeed when scientists and engineers fail to appreciate the underlying causes of the threats to water security and fail to fully engage with relevant players to understand the problem and discuss the advantages and disadvantages of alternatives.

Mindful of the water security challenge facing humankind, the authors of this perspective article felt it was critical to capture all of the opportunities for advancing global water security presented by the Global Water Security Conference community and use the collective wisdom to develop key priorities for scientists, engineers, and other water resource professionals. To capture this collective wisdom, the authors compiled notes from the 2018 ASABE Annual International Meeting keynote address and panel discussion and from all of the conference sessions and presentations. To use this information and develop a list of potential key priorities, we started with the outline of Margaret Catley-Carlson's keynote address at the 2018 ASABE Annual International Meeting and added themes that recurred in the panel discussion and in the Global Water Security Conference session discussions. Then we counted the number of times each term recurred and grouped similar terms to formulate an initial list of key priorities. Several terms (e.g., food waste, wastewater reuse) were consistently emphasized and were clearly key priorities, but others required a bit more rewording and regrouping. We initially considered several additional topics for possible inclusion as stand-alone key priorities (e.g., technology, education, informatics/decision support/models, climate change); but these topics reoccurred throughout the discussion of most of the key priorities; therefore, they are discussed within each of the key priorities. The following sections summarize each of the final seven Key Priorities and discuss opportunities and challenges:

1. Reduce food waste.

2. Increase wastewater reuse.

3. Increase agricultural resiliency and efficiency.

4. Optimize irrigation efficiency and increase crop water productivity.

5. Improve water supply management.

6. Improve water resource infrastructure.

7. Enhance water resource decision-making and policy formulation.

While this perspective article was written mostly for scientists and engineers, who are typically more comfortable discussing and addressing technical aspects of water security, it is essential for us to realize that focusing only on technical aspects rarely results in effective solutions. Ms. CatleyCarlson presented a reality that we far too often forget: that development of successful technical solutions relies on understanding underlying socio-economic factors and vetting with all relevant players the advantages and disadvantages of alternate solutions. She and many of the presenters stated that social sciences (e.g., economics, marketing, communications, sociology, public relations) must be appreciated and incorporated into all phases of water resource engineering design, research, decision-making, and policy formulation; that interdisciplinary teams are crucial for effectively moving technical solutions forward; that all relevant players (e.g., community leaders, industry, agriculture, elected officials) must be involved in discussing problems and probable solutions; and that political dimensions and constraints related to the formulation of coherent public policy are vital to effectively applying technological solutions. Because these non-technical aspects are rarely fully integrated into water resource science and engineering, they are highlighted and discussed within each of the seven Key Priorities and are the sole focus of Key Priority 7.

\section{Key Priority 1: Reduce Food Waste}

The need to reduce food waste to achieve global water security was consistently highlighted at the Global Water Security Conference. For example, in his plenary keynote address, Dr. Sonny Ramaswamy stated that addressing food waste is a critical component of addressing global food, energy, and water security, and Dr. Vimlendra Sharan (FAO Liaison Office, Washington DC, U.S.) listed reducing food waste as one of seven key actions needed to address the current or soon to come water crisis. Worldwide, approximately one-third of the food produced for human consumption annually ( 1.3 billion Mg) is lost or wasted (FAO, 2011). The large amount of water required to produce the wasted food, about one-third of the $70 \%$ of freshwater used for irrigation globally (Schlosser et al., 2014; FAO, 2016; Dieter et al., 2018), is an unnecessary drain on water supplies because of the linkage between food production and freshwater resources.

To contribute to global water security by reducing food waste, scientists and engineers are encouraged to:

- Recognize the socio-economic context and considerations vital to reducing food waste.

- Support outreach and education on healthy and balanced diets and on nutritional and economic value of wasted food to shift cultural norms related to fruit and vegetable appearance, food waste composting, food donations, etc.

- Recognize the leadership role that women play in food purchase and consumption decisions and the power of 
their influence related to food and dietary decisions.

- Enhance storage and transportation methods.

- Improve food engineering related to pre- and post-processing storage.

- Analyze the complete food supply chain to improve efficiency and reduce wasted energy, water, and food.

\section{Key Priority 2: InCRease Wastewater Reuse}

The need to increase wastewater reuse to achieve global water security was also consistently highlighted. For example, in a conference plenary keynote address, Dr. Asit Biswas (National University of Singapore) discussed the use of treated wastewater for drinking and highlighted the associated challenges related to negative public perception; the fact is that treated wastewater can be safer and more reliable than other water supply alternatives. Ms. Catley-Carlson also acknowledged the "long and troubled history" of wastewater reuse and the need to "break the perceived link from toilet to tap" and instead highlight the benefits of wastewater reuse.

To contribute to global water security by increasing wastewater reuse, scientists and engineers are encouraged to:

- Support outreach and education on the appropriate, science-based public perception of wastewater reuse in agricultural production, recognizing that women are often agents of change.

- Better understand the potential of poor-quality (non-potable) water to reduce use of potable water for irrigation.

- Strengthen outreach and education with research on the costs/benefits, agronomic impacts, and health implications of crops grown with wastewater, as well as on conjunctive use of wastewater with fresh water for crop production.

- Determine "how clean is clean enough?" for water's next use.

- Improve technology to enhance wastewater reuse (e.g., removal of organic compounds, surfactants, and heavy metals; membrane filtration systems; nanotechnology; natural treatment systems).

- Consider the need to address the removal of emerging contaminants (e.g., endocrine disruptors, micro-plastics) that may require new, as yet undeveloped, treatment technologies.

- Develop and use better water treatment and solids removal techniques for utilization of wastewater for irrigating agricultural land and recreational areas (e.g., parks, athletic fields) as well as industrial and municipal use.

\section{Key Priority 3: Increase Agricultural RESILIENCY AND EFFICIENCY}

The need to maximize the resiliency and efficiency of agricultural systems was evident, with various aspects of enhanced agricultural production (e.g., improve soil chemical, physical, and biological function; optimize nutrient and water application; and use precision agriculture and biotechnology) highlighted as critical to achieve global water security. There is no doubt of the urgent need to optimize water and nutrient (fertilizer) application for natural resource protection and on-farm economic sustainability. Dr. Praveen Rao
(Professor Jayashankar Telangana State Agricultural University) referenced the "Global Trends 2030" report (NIC, 2012), which listed precision agriculture (optimization) as one of five technologies that will change the world.

In the Farmers' Panel Discussion at the Global Water Security Conference, farmers from the U.S. and India noted the need to increase resiliency and efficiency with no-till farming and improved rice paddy management; using machinery advances including dry seeded rice planters, laser or GPS guided land leveling, raised-bed planters, and no-till drills; improving soil health and nutrient cycling by enhancing soil biology and increasing soil organic matter, optimize fertilizer utilization, and increase yields; and improving residue cover on the soil surface to reduce erosion and surface evaporation and store more water. One noteworthy comment that particularly resonated was the importance of adjusting inputs in relation to uncontrollable production factors, and one farmer stated that in water-short areas, the farmer with low input costs will be the survivor. The farmers unanimously recognized that they must adjust their management techniques, recognizing the associated pros and cons. They mentioned planting earlier to avoid summer hot/dry periods and pest pressure, which means colder temperatures at planting, and planting crops such as sorghum and millet that use less water. When asked about the biggest risk to staying in business, they noted changing weather has always been an issue. The farmers said that high input and capital costs (e.g., seed, pesticides, equipment), increasing land prices, labor shortages, price instability, and shrinking profit margins were now especially challenging, which highlighted the importance of governmental intervention to stabilize agricultural production (for additional information, see Key Priority 7).

Using crop breeding, biotechnology, and natural plant genetic diversity is another important tool for improving agronomic efficiency. Great progress has been made in recent years related to drought resistance and changes such as the ability to grow rice without standing water. The USDA National Plant Germplasm System's National Laboratory for Genetic Resources Preservation and Plant Introduction Stations and international centers such as CGIAR's International Crops Research Institute for the Semi-Arid Tropics (ICRISAT, India) and the International Maize and Wheat Improvement Center (CIMMYT, Mexico) are critical repositories and research hubs for these activities. Overall genetic improvements by developing higher-yielding varieties is contributing to improved crop water productivity even when drought tolerance is not the objective. In most cases, the genetic yield gain is not associated with an increase in plant water use but rather is a result of partitioning more plant energy into the harvestable portion of the crop.

To contribute to global water security by increasing agricultural resiliency and efficiency, scientists and engineers are encouraged to:

- Ensure that outreach, education, and technology transfer on increasing agricultural resiliency effectively reaches both men and women in developing countries, where women represent a large share of small-holder farmers and hands-on-managers, and in developed countries, 
where women manage or provide labor in many operations.

- Work more closely with producers to learn their needs and use their experience in developing improved agronomic practices.

- Develop implements and tools for efficiently performing agricultural operations on the small holdings prevalent in most developing countries.

- Actively participate in outreach and education related to the on-farm practices and societal importance of increasing agronomic efficiency.

- Focus outreach and technology transfer on practical, science-based strategies and intuitive (user-friendly), effective, and affordable technologies.

- Commit to developing effective partnerships between government agencies, industry, academics, non-profit organizations, and other professionals to enhance implementation of the aforementioned strategies.

- Implement and use enhanced soil testing methods and consider all nutrient sources (e.g., rainwater, irrigation water, mineralization, deeper soil layers) in developing more comprehensive nutrient budgets.

- Develop appropriate nutrient recommendations, recognizing regional constraints of weather as well as water and fertilizer availability.

- Develop proximal crop sensors to detect nutrient and water status and inform rate adjustment for within-season nutrient and water applications.

- Develop user-friendly mobile apps and dashboards for efficient use of resources (e.g., water, nutrients).

- Use crop breeding, biotechnology, and natural plant genetic diversity to mitigate the impacts of drought, disease, and pest resistance and increase nutrient use efficiency and crop yield potential.

- Create affordable, user-friendly unmanned aerial vehicle (UAV) systems and associated accurate and robust decision support tools for farmers and ranchers to use in nutrient and pest management.

- Improve crop simulation models such that they are userfriendly, accurate decision support tools for improving a diverse range of crop management decisions based on current and predicted weather, pricing, and changing agricultural production conditions and cropping patterns.

- Improve crop simulation models to better use near realtime inputs such as spatially distributed weather data, plant and soil sensor data, and GPS data from farm machinery (e.g., crop condition, crop yield).

- Focus not only on practices that increase yields but also on those that increase on-farm profits and sustainability.

\section{KEY PRIORITY 4: OPTIMIZE IRRIGATION EFFICIENCY and InCrease Crop Water Productivity}

The need to improve irrigation efficiency by optimizing water delivery (conveyance) and application to crops to achieve global water security was evident. Equally important to increasing irrigation efficiency (defined herein as the fraction of the amount of water diverted that is delivered to the root zone and available for crop uptake) is the need to increase crop water productivity, which is the yield per unit of water consumed for crop growth. Because various terms are used to describe how efficiently irrigation water is applied and/or used by the crop, and because misuse and misrepresentation of irrigation performance is common, Rogers et al. (1997) suggest that reporting both application efficiency and water distribution uniformity provides a better indication of overall irrigation system performance.

In his comments as an invited panelist, Dr. Indrajeet Chaubey told of irrigation's profound impact on his family. His grandfather was a subsistence farmer in India who once worried about his ability to grow enough food to feed his family but later received a federal loan to buy a diesel engine to run a pump to convert from dryland (rainfed) agriculture to irrigated agriculture. There is no doubt that irrigation has changed the face of the world, turning the desert green in many areas, and increasing production to feed and clothe the world; however, irrigation has also decreased groundwater levels, increased energy consumption, and contributed to negative environmental impacts through leaching of nutrients and other chemicals to groundwater due to suboptimal management practices and strategies. Additionally, application of large quantities of irrigation water without appropriate drainage improvements has caused waterlogging and secondary salinization in many semi-arid regions (Ritzema, 2006). In addressing the water crisis, Dr. Vimlendra Sharan emphasized the need to optimize irrigation application and access (note that other topics related to irrigation, i.e., infrastructure and water supply management, are discussed under Key Priorities 5 and 6). A related issue involves capitalizing systems that are under-capitalized, especially irrigated systems because of the capital costs. Access to credit (or microcredit), to inputs and markets, and to infrastructure, all play important roles in developing irrigated agriculture systems that are sustainable and create wealth (see the "Anchor Farm" approach by the Clinton Foundation in Africa).

As pointed out by Dr. Steven Evett in his plenary address, great progress has been made in recent decades toward increasing agricultural productivity with less water due to conversion from flood (gravity) irrigation to sprinkler irrigation, adoption of micro-irrigation (surface and subsurface drip) and low-pressure irrigation systems, and implementation of soil moisture and crop water use sensors. However, adoption of these practices and technologies varies regionally, and in the face of increasing water scarcity, further increases in irrigation efficiency and crop water productivity are needed. In some regions, adoption of micro-irrigation (drip) systems over a larger area may be required to increase water productivity and economic profitability. In horticultural crops, it has been reported that water use can be reduced by $50 \%$ or more with concurrent increases in yield and water productivity of up to $250 \%$ over conventional irrigation methods (Malhotra and Das, 2016). In field crops, reductions in water use of $20 \%$ and increases in water productivity (water use efficiency) of $20 \%$ can be obtained with precision irrigation (O'Shaughnessy et al., 2015, 2016, 2017). The potential trade-offs of modern water-saving irrigation systems (e.g., improved on-farm water productivity but reduced runoff, deep seepage, and groundwater recharge) must also be considered from a watershed perspective. For example, in re- 
gions where runoff of excess irrigation is used by downstream farms, the watershed-level water savings may be much less evident than at the field level. To some extent, however, the goal should be maximizing the yield per unit of available water, rather than water savings, whether from the single field, farmstead, or basin perspective.

Although irrigation technology has been improved substantially (e.g., center pivot and drip), advances in information-based irrigation management have lagged. Dr. Evett discussed the use of proximal wireless sensors, sensor networks (both above ground and in the soil), and remote sensing of plant and soil water status to guide precision variablerate irrigation and watershed-level water management. These sensors then become part of the internet of things (IoT) approach to data gathering and system management, which is advancing worldwide, particularly in China, India, and the U.S. When used with pressurized irrigation systems, these sensor systems are facilitating the $4 \mathrm{R}$ approach to irrigation management: right place, right time, right amount, and right quality. When integrated with an automatic decision support system, they provide near real-time assessment of crop water stress to regulate deficit irrigation while reducing the risk of drastic yield declines. As reported in a companion article (Evett et al., 2020), such integrated sensor and decision support systems regularly result in increased crop water productivity. Further, the ubiquitous availability of geographical positioning systems (GPS) and geographical information systems (GIS) with sensor systems and decision support allows near optimal application of 4R irrigation management, 4R nutrient management, and conservation practices (Clay et al., 2017; Delgado et al., 2018; Shannon et al., 2018), which can certainly improve irrigation efficiency and water productivity.

In both developed and developing countries, affordable sensors and user-friendly decision support tools are needed to guide on-farm irrigation management; however, the problem is often not a lack of innovation but a lack of adoption and utilization at large enough scales to make a difference. Where on-farm sensors are not practical over a large areal extent, well-calibrated and extensively validated remote sensing based real-time soil moisture and evapotranspiration (ET) estimation methods can be useful for developing decision support for efficient scheduling of irrigation over large areas. Several remote sensing based tools with worldwide coverage already exist (e.g., Global Root-Zone Soil Moisture Monitoring tool; https://geo.fas.usda.gov/GADAS/index.html; click on Crop Condition and then on Soil Moisture) or will be available in the near future to map ET at multiple scales. ET data cubes, which are two-dimensional arrays of ET values, can be prepared by fusing data from multiple satellites to map daily crop water use at scales down to $30 \mathrm{~m}$. They are already in use by large growers in California, and the technology is adaptable to any part of the world. Whether based on satellite, UAV, or proximal plant and soil sensing, decision support systems (DSS) must be adapted to the irrigation system and farmer culture. In the U.S., farmers are increasingly accepting of internet and smartphone technologies and are currently using or are open to receiving irrigation decision support via these technologies. A major manufacturer of center-pivot irrigation systems has stated that more than $99 \%$ of its systems worldwide have cellular service that allows two-way data and control transmission and that producers expect to receive irrigation decision support via these technologies. In fact, one of the farmers from the U.S. in the Farmers' Panel Discussion was able to see and control her irrigation system in Arkansas by smartphone from India. With the near worldwide ubiquity of cellular telephone service and the increasing areas brought under easily controlled pressurized irrigation, the rapid deployment and acceptance of these tools appears feasible. Dr. Evett discussed one such decision support system based on IoT proximal sensor networks that has been licensed by a major U.S. manufacturer of center-pivot irrigation systems (Evett et al., 2014; Andrade et al., 2017). That system has been shown to allow regulated deficit irrigation of crops (corn, cotton, potato, sorghum, and soybean), reducing yield reduction risk while increasing overall crop water productivity relative to conventional irrigation scheduling (e.g., O'Shaughnessy et al., 2015, 2016, 2017).

Although the IoT and DSS technology revolution appears imminent, the adoption of "smart irrigation" technology remains limited. For example, adoption of smart irrigation technology, such as infield soil sensors, is not more than $20 \%$ in U.S. cotton, according to Dr. Barnes. Dr. A. Reddy (National Institute of Agricultural Extension Management, India) discussed the social learning (educational) aspects of technology adoption, stressing the success of local water user associations in producer training and establishing links with industry to support operation and utilization. Engineering and science societies, such as the ASABE, ISAE, and the American Society of Agronomy (ASA), have a role to play here, particularly in transferring knowledge by way of books, guides, specialized conferences, and training. For example, conference co-sponsor ASA provides science-based training and certification to more than 13,000 certified crop advisors in North America. The training includes specializations in nutrient management and precision agriculture, including both precision conservation and precision irrigation. However, the lack of access to irrigation (or adoption of irrigation) is still a limitation to crop production in many African countries and other developing nations. It also limits crop production in certain humid regions, such as the eastern U.S. where crop production reaches only $50 \%$ of potential because of short-term drought at critical times in the growing season but increases to $80 \%$ of potential production with irrigation, according to Dr. Evett. For this reason, irrigation is being rapidly adopted in humid areas of the U.S.

To contribute to global water security by optimizing irrigation efficiency and increasing crop water productivity, scientists and engineers are encouraged to:

- Ensure that outreach, education, and technology transfer related to optimizing irrigation efficiency and increasing crop water productivity effectively reach both men and women in developing and developed countries.

- Develop effective, science-based outreach and education programs for irrigation technology and management by working closely with growers to enable broad-scale technology implementation aimed at achieving large-scale regional impacts. 
- Ensure that technological advances are designed to be intuitive (user-friendly), effective, and affordable such that they are widely adopted and used by farmers.

- Ensure that outreach and education stress the importance of adopting appropriate drainage improvements and irrigation management where needed to avoid secondary salt buildup in the soil.

- Develop better understanding of the crop production and water use impacts of deficit and limited irrigation.

- Develop and provide recommendations for crop production systems that couple appropriate irrigation and nutrient application (rate, timing, etc.) with crop type.

- Develop affordable sensors and wireless sensor networks coupled with accurate, user-friendly decision support tools to guide on-farm irrigation management, including limited and deficit irrigation.

- Create affordable, user-friendly UAV systems and associated decision support tools for farmers and ranchers to use in irrigation, nutrient, and pest management through detection of crop health, leak detection, plant stress, crop emergence, and disease and pest pressure.

- Incorporate advances in irrigation technology into onfarm decision support systems that consider crop selection, water harvesting, and/or tillage and nutrient management.

- Develop methods and tools for using satellite-based soil moisture and ET data for accurate estimation of crop irrigation water requirements and use that information for developing decision support tools.

- Improve crop simulation models such that they are userfriendly decision support tools for improving irrigation management decisions based on current and forecasted weather and pricing conditions.

- Identify climate change impacts on local agricultural practices and develop effective adaptation and mitigation strategies related to improving irrigation efficiency and crop water productivity.

- Strengthen partnerships between researchers and industry to enhance technology development and transfer.

\section{Key Priority 5: IMPRove WATER SUPPLy MANAGEMENT}

While improving on-farm water management and supply is an important need, improving local, regional, and national water supply management was also consistently highlighted as critical to achieving global water security. In fact, Dr. Vimlendra Sharan emphasized this need as one of seven key actions to achieve global water security. Dr. Asit Biswas asserted that in many countries (specifically India, China, and U.S.) the problem is not a lack of water but the mismanagement of water; although water availability is indeed a problem in other areas. Dr. Harshadeep Nagaraja Rao from the World Bank also encouraged the use of "disruptive technologies," which he defined as "not doing things differently but doing different things." In better managing water supplies, systems-level thinking is a must, and disruptive technologies must be considered. Supply/demand-driven strategies within new and enhanced existing regional plans are needed to optimally allocate and use water resources. For example, water supply management strategies in California have evolved and become demand-driven using sensor and telemetry system advances. For supply systems with pressurized pipe networks, this provides dual benefits of reducing conveyance losses and providing water under pressure for pressurized irrigation systems (e.g., low-pressure sprinkler and microirrigation).

The critical nature of data informatics and modeling/decision support tools to optimize local, regional, and national water resource decisions was also a recurring theme. Dr. Venkat Rao (Indian Space Research Organization) highlighted water informatics efforts in India to improve water management. The Water Resources Information System of India (WRIS) web portal was launched in 2009 to keep water-relevant data in the public domain. WRIS provides a comprehensive, credible, contextual view of Indian water resources and is used for many purposes, such as forecasting agricultural droughts and identifying areas with extreme groundwater withdrawal. This national effort inspired many regional water information systems, such as the Telangana Water Resources Information System (TWRIS), which georeferenced $\sim 45,000$ tanks (ponds) and reservoirs. While such information systems are important, especially when they can accurately account for water supplies, they are even more valuable when linked with modeling frameworks and decision support tools.

Regional and national decision support systems (e.g., U.S. Army Corps of Engineers Corps Water Management System, CWMS) can be used to effectively and efficiently manage water supplies if they are practical, science-based, and accurately reflect current and anticipated hydrologic, meteorologic, and geographic conditions. Such decision support systems are critical for evaluating and predicting the location and severity of water stress in irrigated agricultural systems, locating and sizing water conservation structures, and assessing water resources vulnerability under climate or land use change scenarios.

Dr. Vimlendra Sharan also highlighted participatory irrigation management as a key component of improving water supply and irrigation management in public irrigation programs. In India, this approach is used to supply water to water user associations, who take over the responsibility of irrigation supply operation, maintenance, and management in their area. This approach has proven beneficial to both farmers and the government through improved equity of distributed irrigation water, cost-effective maintenance of irrigation infrastructure, and increased freedom of producers to proactively plan cropping schemes and management.

To contribute to global water security by improving water supply management, scientists and engineers are encouraged to:

- Commit to close collaboration and coordination between researchers and practitioners.

- Develop effective, science-based outreach and education programs for water supply management, working closely with growers to enable broad-scale technology implementation aimed at achieving large-scale regional impacts. 
- Develop cost-effective control methods for invasive species (e.g., water hyacinth) that decrease surface water supplies.

- Continue to improve UAV systems and other remote sensing technology and associated decision support, data management, and data analysis tools for use by regional and national water supply managers to allocate, inventory, conserve (e.g., by identifying leaks in conveyance systems), and assess water resources.

- Improve crop simulation models to more accurately evaluate climate change impacts on plant growth and water use for estimating irrigation water demand and informing hydrologic models.

- Ensure that regional hydrologic models adequately represent natural and altered hydrologic processes and climate change impacts to allow proactive, long-term water supply planning.

- Promote participatory irrigation management and public/private partnerships for irrigation supply management.

- Develop strategies for enhancing canal delivery system performance and minimizing losses, including conversion to piped systems with demand-driven management.

\section{Key Priority 6: Improve Water Resource INFRASTRUCTURE}

Throughout the Global Water Security Conference, speakers emphasized the need for improved water resource infrastructure (e.g., water harvesting, storage) to achieve global water security in the face of changing climate and rainfall patterns. In countries such as India where more than $70 \%$ of the available water is withdrawn for agriculture, rainfall conservation is a key option to sustain crop production. In a conference plenary keynote address, Dr. Asit Biswas stated that developing infrastructure for water storage and delivery is one of the biggest challenges to achieving global water security and that we must more effectively store water with rainfall harvest and storage in dams of all sizes. Similarly, Dr. Harshadeep Nagaraja Rao noted a deficit in the investment in infrastructure, which is needed to prepare for disasters and increase resiliency when they occur. Construction of on-farm water storage reservoirs is increasing rapidly in humid regions of the U.S., especially where tile and openditch drainage systems are prevalent. Such on-farm storage, which is now being supported with government assistance, allows runoff following heavy rains to be used for irrigation during subsequent short-term droughts to limit yield reduction, as discussed by Dr. Evett and Dr. Reba.

Dr. Anju Gaur from the World Bank also pointed out a simple truth, which is too often ignored, related to water storage and in discussions of water security: sedimentation in surface water supplies can greatly reduce usable water storage capacity. Dr. Gaur emphasized the need to remove excess sediment from reservoirs, acknowledging the high cost of dredging and the need to budget for this cost. He also highlighted the benefits of proactive erosion control to extend the useful service life of reservoirs, the cost of which is far less than dredging.

In the U.S., almost 12,000 embankment dams were constructed under the Flood Control Act of 1944 (PL-534) and subsequent Watershed Protection and Flood Prevention Act of 1956 (PL-566) to provide flood protection and other benefits (e.g., rural and municipal water supply, irrigation, wildlife habitat, and recreation); however, many of these dams are beyond their 50-year planned service life. Although these dams provide an estimated \$3 billion in annual benefits (USDA, 2019), maintenance and repair have lagged, and many dams have deteriorated structural integrity and reduced flood pools filled with sediment. In addition, the hazard classification of many dams has changed due to urban development adjacent to and immediately downstream. If investment continues to lag, it will become even more important to enhance models like Windows Dam Analysis Modules (WinDAM) for predicting earthen dam erosion due to overtopping and/or internal erosion or develop new innovative embankment overtopping protection technologies. Furthermore, retention of institutional knowledge and technical capacity to address aging water resources infrastructure, specifically dams, has declined significantly over the years. For example, Freeland et al. (2011) reports a decline of more than $50 \%$ in the USDA-NRCS technical staff supporting dam infrastructure, as compared to the technical staff supporting the infrastructure during the peak of construction in the 1960s. The scientific community has experienced similar declines in staffing needed to develop innovative technologies to support water resources infrastructure in the dam sector.

Replacing open canals with pipe networks is an infrastructure improvement that is often discounted as being too expensive; however, the benefits of pressurized irrigation water delivery and distribution are clear. The benefits accrue from both decreased conveyance losses and improved uniformity of distribution both in single fields and across irrigation perimeters. In the U.S., the amount of water used in irrigation has declined from $640 \mathrm{~mm}$ to $490 \mathrm{~mm}$ (average depth) as pressurized water distribution increased from $18 \%$ in 1969 to $>65 \%$ today (USDA, 2014), and since 1980 irrigation water demand has steadily declined even as the irrigated area increased from 20.2 to 22.3 million ha. As demonstrated by Dr. Evett, the opportunities for improved control and utilization of decision support systems expand in conjunction with the availability of pressurized irrigation and distribution systems. It is important to recognize that although pressurization may be accomplished using elevation changes and penstocks (sluices) in some cases, pressurization typically has an energy cost, which inhibits the adoption of pressurized irrigation in some areas (e.g., Spain). Increasing the adoption of pressurized irrigation through energy development (e.g., renewable energy, local energy sources) will accelerate its already increasing adoption, bringing this advancement to more of the world.

The importance of and interest in water harvesting by the conference attendees cannot be overstated. In fact, a call was made for a joint ISAE and ASABE conference dedicated to water harvesting to allow both governmental and non-governmental agencies to discuss this subject in detail considering both socio-economic and scientific/technical perspectives. Water harvesting and storage is also a crucial contemporary topic, as exemplified by government investments and small-scale farmer initiatives (as described in the Farmer's 
Panel Discussion). For example, the Indian state of Telangana is investing billions (INR) to build infrastructure to enhance the capture and storage of rainwater (water harvesting). This effort resulted in part from Telanganan farmers who attempted to take their water future into their own hands by drilling costly wells. The wells later ceased producing adequate water, causing considerable frustration to the farmers, and the government stepped in. This example highlights the need for regional planning and investment to optimize effectiveness and efficiency in water resource management and investment. The Farmer's Panel Discussion also identified numerous examples in which farmers implemented smallscale, on-farm water harvesting techniques such as irrigation practice changes to use more recaptured water, simple artificial recharge techniques to guide runoff to wells (although artificial recharge through porous media would be preferred to mitigate adverse water quality impacts), and constructed wetlands to treat wastewater and store water for irrigation of grain crops and flowers. In addition, given amenable soil profile conditions, shallow groundwater recharge using traditional farm ponds has the potential to greatly increase the volume of runoff storage without removing more land area from crop production.

To contribute to global water security by improving water resource infrastructure, scientists and engineers are encouraged to:

- Ensure that extension education related to water resource infrastructure effectively reaches both women and men in developing and developed countries.

- Incorporate farmer recommendations and expertise when designing small-scale and on-farm irrigation infrastructure (e.g., dug-wells, reuse pits, farm ponds).

- Partner with state and federal agencies to establish and/or increase incentive programs for designing and constructing centralized or de-centralized water reuse and storage infrastructure.

- Ensure that regional hydrologic models adequately represent natural and altered hydrologic processes and climate change impacts to support infrastructure needs and designs.

- Where feasible, replace open canals with pipe networks fed by reservoirs, particularly for smaller canals (nearer to farms), which have a majority of the canal length and are often in the worst condition (e.g., unlined, poorly maintained).

- Develop cost-effective control methods for invasive species (e.g., water hyacinth) that decrease the effectiveness of water resource infrastructure.

- Identify appropriate locations for water harvesting and water storage using models, decision support tools, and local expertise.

- Increase research on options for on-farm shallow groundwater recharge and develop guidelines on the geological conditions where this practice is feasible.

- Promote and design sustainable decentralized water harvesting methods to capture water on production fields and return that water for reuse while balancing the benefits of reduced water and nutrient loss with the water needs of downstream water users.
- Develop innovative dam protection strategies (e.g., improved overtopping and wave erosion protection systems).

- Develop enhanced computational models (e.g., Windows Dam Analysis Modules, WinDAM) to better predict erosional processes and subsequent breach failure potential.

- Capture the institutional knowledge of dam safety professionals and integrate curricula in academic institutions to better train the next generation of engineers to deal with aging water resource infrastructure (e.g., dams, grade stabilization).

\section{Key Priority 7: Enhance Water Resource DECISION-MAKING AND POLICY FoRMULATION}

The critical need for enhanced decision-making, including processes used to develop and implement public policy, to achieve global water security was evident throughout the conference. Enhancements needed to improve water resource decision-making and the effectiveness of public policies include: learn from history, use sound science and engineering, accept social responsibility, and consider socioeconomic realities.

Whether making on-farm decisions or formulating and implementing national policies, humankind far too often fails to learn from history and thus repeats previous mistakes. Dr. Vimal Mishra (Indian Institute of Technology, Gandhinagar) provided a profound reminder of this folly in his invited presentation describing the important droughts in India's history based on weather, soil moisture, severity, spatial extent, and duration. His team concluded that before 1900 most famines were caused by droughts but that more recent famines were caused by failed policy (e.g., excessive food export). The mortality rate in recent famines was dramatically reduced, which is attributed to a drastic increase in the number of on-farm wells enabling groundwater to supplement reduced rainfall; however, groundwater in India has become severely depleted, which will reduce the ability of groundwater resources to mitigate drought effects in the future.

Water resource decisions and public policies should also be scientifically sound so that technological solutions are effectively applied to address water scarcity at regional and national scales. In his policy prescription for a water and food secure future, Dr. Vimlendra Sharan highlighted the need to effectively integrate science and policy to address the complex interactions between water, food, and energy security. Dr. Barnes emphasized the importance of discussing the benefits of irrigation (e.g., increased production, less land needed, reduced production risk) as well as negative consequences (e.g., decreasing groundwater, increased energy consumption) in policy debates. Appropriate consideration of relevant trade-offs based on expert input from scientists and engineers is critical in water resource decisionmaking to avoid singular actions and unintended consequences, such as providing free power for irrigation water pumping, which led to unsustainable groundwater depletion in some regions.

Water resource decisions and policies directly impact hu- 
man health and well-being. Aware of the grave consequences and the need for decisions focused on the common good, Dr. Vimal Mishra emphasized the need to ensure that all decision-makers are aware of the "grand challenge of food and water security." Dr. Gajendra Singh (Indian Agricultural Research Institute) made a similar plea for scientists and engineers, as members of ISAE and ASABE, to help educate the public and elected officials about the critical nature and need for global water security, focusing on the societal good rather than short-term personal or political goals. The critical role of education was reinforced by Dr. V. Praveen Rao when he said that achieving global water security will rely not only on scientific effort but also on the effort to educate children, educate the public, and educate producers through outreach and extension. To achieve global water security, the public in general, including women, children, elected officials, and decision-makers, must all understand and internalize the problem of water scarcity and its dire consequences and detrimental impacts.

Dr. Asit Biswas's comments from a previous chat with Mrs. Kasturba Gandhi (wife of Mahatma Gandhi) highlighted the importance of appropriately considering socioeconomic realities in water resource decision-making and policy formulation and implementation. He recalled that Mrs. Gandhi insisted that they not talk about water but that they instead talk about water as a catalyst for economic development and social stability. In a similar vein, Ms. CatleyCarlson emphasized the need for trans/interdisciplinary teams to develop and implement sustainable water technology, management, and policy. While engineers and scientists bring forward technological solutions, social science (e.g., economics, sociology, marketing, communications, public relations, and education) is needed to move the solutions forward. As Ms. Catley-Carlson said, "Water problems are not solvable by the water department." Therefore, we need to "break down the silos before defining and then solving the water security problem." Dr. Barnes made a similar plea to involve all relevant players in discussing water security problems and formulating probable solutions, including community leaders, industry, and agriculture. Ms. Hadda said it well: "When engineers and scientists can come together with farmers, entrepreneurs, rural residents, urban dwellers, industrial users, and government policymakers, we have the greatest opportunity to find solutions to complex problems in water security and agriculture."

One particular socio-economic reality that is critical in addressing water scarcity is the recognition that women (and to a lesser degree youth) are agents of change. Whether in developing countries, where women represent a large share of small-holder farmers and hands-on managers, or in developed countries, where women lead or partner in managing large holdings or provide a substantial portion of farm labor, women are often hindered by ineffective and unfair policies. Public policies must appropriately address gender and socioeconomic class to be effective and equitable, and not simply mention gender and class differences but do nothing to address real-world challenges. To have a profound impact on many of the seven Key Priorities discussed herein, women must play a crucial if not leading role.
Another critical socio-economic reality related to achieving global water security hinges on the value of water. Dr. K. Yella Reddy (Acharya N.G. Ranga Agricultural University) implored us all to "value" water: "Water is an economic good. Trade in virtual water. Respect agriculture." Virtual water (defined as the amount of water used to produce consumer goods) was a recurring topic throughout the conference, as was the need to account for the cost of water (and energy) used to produce crops. It is crucial in trade decisions and policy to consider the fact that water is "exported" when exporting agricultural commodities and other products and to use the concept of virtual water to manage water scarcity and improve water productivity. Although political and social costs will likely create pressure against such actions, water must be appropriately valued and accounted for in decision-making and public policy if global water security is to be realized.

To contribute to global water security by enhancing water resource decision-making and policy formulation, scientists and engineers are encouraged to:

- Be active in educational efforts related to water security to support agriculture and natural resources, and its societal importance.

- Engage with social scientists when formulating new water plans to understand the implications of new management practices on grower behavior and the impact of others in the community.

- Engage with technology transfer and education experts to find ways to more effectively explain the benefits of improved water management to both large- and smallholder farmers.

- Produce accurate, science-based information related to the definition and determination of virtual water and the "water footprint" of agriculture, as misinformation and improper assumptions on the subject are commonly applied.

- Become educated and help educate the public and elected officials about the critical nature and need for global water security, focusing on the societal good rather than short-term personal goals.

- Assess water use trends considering both urban and agricultural needs.

- Produce realistic estimates of climate change impacts on water resources to inform planning and policy.

\section{CONCLUSION}

The synchronous occurrence of rapid growth in the human population, the growing middle class and its changing dietary demands, climate change, trade globalization, public mistrust of science, and the substantial cost of ensuring sustainability threatens the world and highlights the need for global water security. Thus, as scientists and engineers, we must do our part to support global water security. Herein we summarize recommended actions organized in seven Key Priorities (Reduce food waste, Increase wastewater reuse, Increase agricultural resiliency and efficiency, Optimize irrigation efficiency and increase crop water productivity, Im- 
prove water supply management, Improve water resource infrastructure, and Enhance water resource decision-making and policy formulation) as distilled from contributions of international water resource professionals. Critical non-technical aspects, which are rarely fully integrated into water resource science and engineering, are highlighted and discussed within each of the seven Key Priorities.

Scientists, engineers, and other water resource professionals can no longer focus solely on the technical aspects of water security. Instead, we must ensure that all relevant players are included and understand the socio-economic realities that contribute to the problem and participate in discussing and developing proposed solutions. Effective, implementable solutions will only come from multidisciplinary and interdisciplinary teams that appreciate both the technological and human dimensions of developing solutions to address the looming global water scarcity crisis. If the technical water resource community continues to focus narrowly on technical solutions, then those solutions will most likely fail. May we instead work together, across all disciplines and across all boundaries, to ensure global water security.

\section{ACKNOWLEDGEMENTS}

ASABE and the authors recognize that the efforts of many people contributed to the success of the Global Water Security Conference. The following individuals served as committee chairs: Dr. Indrajeet Chaubey and Dr. Indra Mani (Conference Co-chairs), Dr. Daren Harmel (Chair, Publication), Dr. Gajendra Singh and Dr. Mary Leigh Wolfe (Cochairs, Advisory), Dr. Dharmendra Saraswat and Dr. Suat Irmak (Co-chairs, Development), Dr. Srinivasulu Ale and Dr. Srinivas Reddy Konda (Co-chairs, Local Arrangements), Dr. Lalit Varma and Dr. Mary Leigh Wolfe (Co-chairs, Partners), Dr. Garey Fox and Dr. Dorota Haman (Co-chairs, Program), and Dr. Lalit Varma and Dr. Indra Mani (Co-chairs, Publicity).

It is also important to recognize the following sponsors and supporters whose financial contributions made the conference possible:

- Lead Sponsor: Irrigation and CAD Department, Government of Telangana.

- Conference Partner: American Society of Agronomy.

- Platinum Sponsors: Department of Tourism, Government of Telangana; Professor Jayashankar Telangana State Agricultural University; USDA-NIFA; and Taj Krishna.

- Gold Sponsors: Purdue University; Indian Council of Agricultural Research; Jain Irrigation Systems, Ltd.; UM International, LLC.

- Silver Sponsors: USDA-ARS; Indian National Bank for Agriculture and Rural Development.

- Bronze Sponsors: University of Arkansas; Science and Engineering Research Board, Government of India.

- Conference Champions: Cotton Incorporated; Michigan State University; Cornell University; Texas A\&M University; Hyderabad Convention and Visitors Bureau; Virginia Tech University; International Water Management Institute; University of Nebraska-Lincoln.

- Conference Supporters: Irrometer Co.; Netafim; Council of Scientific and Industrial Research, India.

\section{REFERENCES}

Andrade, M. A., O'Shaughnessy, S. A., \& Evett, S. R. (2017). Sitespecific irrigation management of a center-pivot irrigation system using a sensor-based decision support system. Proc. Irrigation Association Tech. Conf. Fairfax, VA: Irrigation Association.

ASABE. (2015). Global partnerships for global solutions: An agricultural and biological engineering global initiative. St. Joseph, MI: ASABE. Retrieved from https://www.asabe.org/Portals/0/PublicAffairs_Std/GlobalInitiati ve/globalinitiative.pdf.

CAST. (2019). Aquifer depletion and potential impacts on longterm irrigated agricultural productivity. IP63. Washington, DC: Council for Agricultural Science and Technology.

Chaubey, I., Bosch, D. D., Munoz-Carpena, R., Daren Harmel, R., Douglas-Mankin, K. R., Nejadhashemi, A. P., ... Shirmohammadi, A. (2016). Climate change: A call for adaptation and mitigation strategies. Trans. ASABE, 59(6), 17091713. https://doi.org/10.13031/trans.59.12138

Clay, D. E., Clay, S. A., \& Bruggeman, S. (Eds.) (2017). Practical mathematics for precision farming. Madison, WI: ASA-CSSASSSA. https://doi.org/10.2134/practicalmath

Delgado, J. A., Sassenrath, G. F., \& Mueller, T. (Eds.) (2018). Precision conservation: Geospatial techniques for agricultural and natural resources conservation. Madison, WI: ASA CSSA. https://doi.org/10.2134/Precisionconservation.2018.frontmatter

Dieter, C. A., Maupin, M. A., Caldwell, R. R., Harris, M. A., Ivahnenko, T. I., Lovelace, J. K., ... Linsey, K. S. (2018). Estimated use of water in the United States in 2015. USGS Circular 1441. Reston. VA: U.S. Geological Survey. https://doi.org/10.3133/cir1441

Evett, S. R., O'Shaughnessy, S. A., \& Peters, R. T. (2014). Irrigation scheduling and supervisory control data acquisition system for moving and static irrigation systems. U.S. Patent No. US 8,924,031 B1.

Evett, S. R., O’Shaughnessy, S. A., Andrade, M. A., Kustas, W. P., Anderson, M. C., Schomberg, H. H., \& Thompson, A. (2020). Precision agriculture and irrigation: Current U.S. perspectives. Trans. ASABE, 63(1), 57-67.

FAO. (2011). Global food losses and food waste: Extent, causes, and prevention. Rome, Italy: United Nations FAO. Retrieved from http://www.fao.org/docrep/014/mb060e/mb060e.pdf

FAO. (2016). AQUASTAT website. Rome, Italy: United Nations FAO. Retrieved from http://www.fao.org/nr/water/aquastat/water_use/index.stm

Freeland, J. D., Caldwell, L. W., Hunt, S. L., Locke, M. A., \& Moore, J. (2011). Retention of institutional knowledge and technical capacity for repair and rehabilitation of NRCS-assisted watershed dams. Proc. 12th National Watershed Conf. National Watershed Coalition.

ICA. (2012). Global water security. ICA 2012-08. Washington, DC: Intelligence Community Assessment.

Irmak, S. (2015). Inter-annual variation in long-term center pivotirrigated maize evapotranspiration (ET) and various water productivity response indices: Part I. Grain yield, actual and basal ET, irrigation-yield production functions, ET-yield production functions, and yield response factors. J. Irrig. Drain. Eng., 141(5), 04014068.

https://doi.org/10.1061/(ASCE)IR.1943-4774.0000825

Malhotra, S. K., \& Das, M. (2016). Augmenting water use efficiency in agriculture. Proc. World Aqua Congress (pp. 45$60)$.

Marty, M. (2015). Agricultural sustainability: A grower, processor, and retailer initiative. Resource, 22(3), 6-9. St. Joseph, MI: ASABE. Retrieved from http://elibrary.asabe.org/abstract.asp?aid $=45600 \& \mathrm{t}=11$ 
NIC. (2012). Global trends 2030: Alternative worlds. Washington, DC: National Intelligence Council.

O’Shaughnessy, S. A., Andrade, M. A., \& Evett, S. R. (2017). Using an integrated crop water stress index for irrigation scheduling of two corn hybrids in a semi-arid region. Irrig. Sci., 35(5), 451-467. https://doi.org/10.1007/s00271-017-0552-x

O’Shaughnessy, S. A., Evett, S. R., \& Colaizzi, P. D. (2015). Dynamic prescription maps for site-specific variable-rate irrigation of cotton. Agric. Water Mgmt., 159, 123-138. https://doi.org/10.1016/j.agwat.2015.06.001

O’Shaughnessy, S. A., Evett, S. R., Andrade, A., Workneh, F., Price, J. A., \& Rush, C. M. (2016). Site-specific variable-rate irrigation as a means to enhance water use efficiency. Trans. ASABE, 59(1), 239-249. https://doi.org/10.13031/trans.59.11165

Ritzema, H. P. (2006). Drainage principles and applications (3rd ed.). Wageningen, The Netherlands: International Livestock Research Institute.

Rogers, D. H., Lamm, F. R., Alam, M., Trooien, T. P., Clark, G. A., Barnes, P. L., \& Mankin, K. (1997). Efficiencies and water losses of irrigation systems. MF-2243. Manhattan, KS: Kansas
State University Cooperative Extension Service.

Schlosser, C. A., Strzepek, K. M., Gao, X., Gueneau, A., Fant, C., Paltsev, S., ... Reilly, J. M. (2014). The future of global water stress: An integrated assessment. Report 254. Cambridge, MA: MIT Joint Program on the Science and Policy of Climate Change. https://globalchange.mit.edu/publication/16014

Shannon, D. K., Clay, D. E., \& Kitchen, N. R. (Eds.) (2018). Precision agriculture basics. Madison, WI: ASA-CSSA-SSSA. https://doi.org/10.2134/precisionagbasics.2018.frontmatter

USDA. (2014). 2012 Census of agriculture. Farm and ranch irrigation survey (2013). Vol. 3, Special studies, Part 1. AC-12SS-1. Washington, DC: USDA National Agricultural Statistics Servcie. Retrieved from www.nass.usda.gov/Publications/AgCensus/2012/Online_Resou rces/Farm_and_Ranch_Irrigation_Survey/fris13.pdf

USDA. (2019). Watershed projects: $\bar{H}$ elping communities solve natural resource issues. Washington, DC: USDA Natural Resources Conservatoin Service.

WWAP. (2014). The United Nations World Water Development Report 2014: Water and energy. Paris, France: UNESCO. 